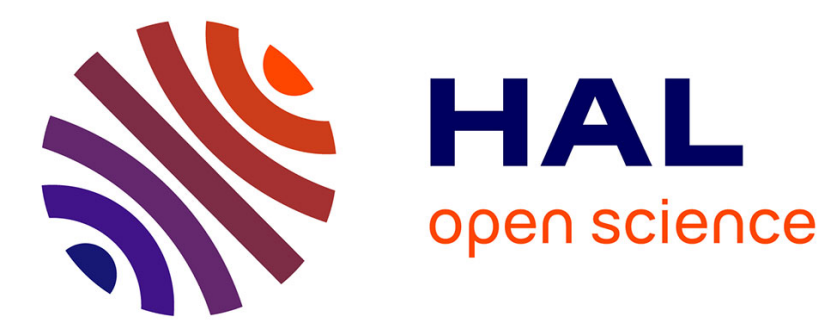

\title{
Counting casualties: A framework for respectful, useful records
}

\author{
Baruch Fischhoff, Scott Atran, Noam Fischhoff
}

\section{To cite this version:}

Baruch Fischhoff, Scott Atran, Noam Fischhoff. Counting casualties: A framework for respectful, useful records. Journal of Risk and Uncertainty, 2007, 34, pp.1-19. ijn_00505176

\section{HAL Id: ijn_00505176 \\ https://hal.science/ijn_00505176}

Submitted on 22 Jul 2010

HAL is a multi-disciplinary open access archive for the deposit and dissemination of scientific research documents, whether they are published or not. The documents may come from teaching and research institutions in France or abroad, or from public or private research centers.
L'archive ouverte pluridisciplinaire HAL, est destinée au dépôt et à la diffusion de documents scientifiques de niveau recherche, publiés ou non, émanant des établissements d'enseignement et de recherche français ou étrangers, des laboratoires publics ou privés. 


\title{
Counting casualties: A framework for respectful, useful records
}

\author{
Baruch Fischhoff • Scott Atran • Noam Fischhoff
}

(C) Springer Science + Business Media, LLC 2007

\begin{abstract}
Counting casualties in conflict zones faces both practical and ethical concerns. Drawing on procedures from risk analysis, we propose a general approach. It represents each death by standard features, having either essential value, for capturing the social and cultural meaning of individual casualties, or instrumental value, for relating patterns of casualties to possible causes and effects. We illustrate the approach with the choices involved in attempts to record casualties in Iraq and the Israel-Palestine conflict, and with natural disasters, as exemplified by Hurricane Katrina. We advocate institutionalizing the approach, so that recording casualties increases understanding, rather than suspicion.
\end{abstract}

Keywords Risk analysis · Risk characterization - Casualties · Conflict · Forensics

JEL Classification $\mathrm{D} 74 \cdot \mathrm{D} 78 \cdot \mathrm{D} 81 \cdot \mathrm{F} 51 \cdot \mathrm{H} 56 \cdot \mathrm{I} 18 \cdot \mathrm{N} 40 \cdot \mathrm{Q} 54$

Counting casualties is part of any conflict. The parties must do it both to monitor the conflict's progress and to give it meaning (Department of Defense, 2005; Graham, 2005; Holt, 2006). Without accurate counts, the situation is obscured and the fallen are dishonored. If these failures appear deliberate, then they may aggravate the conflict, by adding insult to injury. Political scientists need these counts for their own reasons: creating narrative accounts, providing policy advice, and testing theories of conflict and reconciliation (e.g., Daponte, 2003; Epstein, 2002; Peterson, 2002; Walzer, 1992).

The work is grim and challenging. The recorders face not only the risks of work in a conflict zone, but also the wrath of those who want the story told a particular way or not told at all. For example, whatever its motives, the Bush Administration has fed suspicions that it was obscuring the cost of the Iraq war by not counting casualties among Iraqi civilians (Fisk,

B. Fischhoff $(\triangle) \cdot$ N. Fischhoff

Department of Social and Decision Sciences, Carnegie Mellon University, Pittsburgh, PA 15213

e-mail: baruch@cmu.edu

S. Atran

Centre National de la Recherche Scientifique, Paris; University of Michigan, John Jay College—City University of New York 
2005) and private security services (Bergner, 2005; icasualties.org, 2005), and by not making its tally of Coalition casualties readily accessible (Conyers et al., 2005; icasualties.org, 2003). Neglecting non-Western civilian deaths has been cited as undermining global cooperation in the struggle against violent extremism (e.g., Human Rights Watch, 2003; Sachs, 2004; Tavernise, 2005).

The issues faced when counting casualties are special cases of concerns that arise when measuring any socially defined phenomenon. We draw on this research legacy in order to develop an approach to recording casualties in conflict zones capable of producing counts that serve the needs of multiple parties, with differing goals and ideologies. The framework treats the recording process as subjective in two senses: It reflects value judgments, regarding what to measure, and professional judgments, regarding how to do the measuring. Explicitly recognizing these two kinds of judgment is essential if science is to inform politics and vice versa. Without that recognition, the recording process can be both biased, by embodying undisclosed values, and ineffective, by investing measurement resources poorly.

The proposed approach also points to the kind of institution needed to develop and implement a recording protocol, namely, one that has both deep technical expertise and broad political respect. We illustrate these issues with secondary analyses of two data sets from the Middle East. Although we focus on international conflicts, the approach could also be used to structure and summarize national deliberations on recording casualties, like the process convened by the U.S. National Center for Health Statistics (2001) in order to standardize death certificates. In this light, we reflect briefly on the expression of these issues in the Hurricane Katrina disaster. For simplicity's sake, we focus on recording fatalities. However, we use the more general term "casualty," recognizing other forms of suffering and the analogous issues faced by their assessment.

\section{Measurement choices}

As an example, consider the task of describing the victims found in the Saddam Husseinera mass graves exhumed in Iraq after his regime fell (Drew and Mabile, 2005). Forensic pathologists can assess a victim's age and sex relatively well, and the cause of death with somewhat less confidence. Forensic science advances by reducing these uncertainties and creating standard procedures, thereby constraining professional judgment, so that practitioners increasingly reach the same conclusions (Goodin and Hanzlick, 1997; Hanzlick, 2005; Institute of Medicine, 2003; U.S. Department of Justice, 1999; Wecht and Weedn, 2005). However, forensic science alone cannot determine which features of each case are worth describing. That choice requires value judgments. Those can either be made explicitly or left embedded in pathologists' professional practices. Our proposal articulates the rationale for those choices and the locus of responsibility for making them, when designing a protocol for recording casualties.

The adequacy of casualty records depends on how they are used. Their purpose can be essential or instrumental. If the purpose is essential, then the information has inherent value. For example, recording victims' sex would partially satisfy the desire to dignify every death by knowing as much as possible about the victim. It would be especially important for a society with different death rituals for women and men. If the purpose is instrumental, the information is a means to an end. That end might be practical, such as determining criminal charges (e.g., victims' sex matters, if penalties differ for killing men and women). Or it might be scientific, such as understanding a regime's intimidation practices (e.g., victims' 
sex matters, if it clarifies how they are selected) (Human Rights Watch, 2005; Peterson, 2002).

The same information could serve both instrumental and essential purposes, each demanding different degrees of precision. For example, burial practices might require unambiguously determining features (e.g., age, sex, cause of death, religion) that a scientist might find value in knowing approximately. ${ }^{1}$ Instrumental features often define a survivor population, whose size allows estimating casualty rates (Viscusi and Zeckhauser, 2004). Essential features often focus on individual casualties, perhaps making it unseemly to consider the population of those "merely" exposed to the threat.

Any procedure for recording casualties will serve some purposes better than others. For example, instrumental purposes conflict when scientists disagree about whether to perform a small number of costly DNA tests or a large number of inexpensive physical exams. Essential purposes conflict when records that satisfy one audience ignore features that are vital to another audience — or include features that it abhors. Instrumental and essential purposes conflict when religious beliefs proscribe autopsies that provide information critical to scientists or law enforcement officials. For example, in the United States, some archaeologists and some Native Americans have disagreed over whether to study or re-inter "Kennewick Man," whose prehistoric remains were found in Washington State (Slayman, 1996).

Indeed, whether casualties are recorded at all represents a value judgment. In a widely cited quote, ${ }^{2}$ U.S. General Tommy Franks responded to a question regarding the progress of the Afghanistan campaign with, "We don't do body counts." That aspect of the U.S. casualty recording protocol could mean different things to different people. An instrumental argument supporting this policy is that it avoids a practice that, some say, distorted U.S. conduct of the Vietnam War, where body counts emphasized the number of enemy dead, rather than the social, economic, political, and environmental impacts of U.S. actions (Graham, 2005). An instrumental argument opposing this policy is that not counting casualties loses information that is essential to understanding the war. An essential argument supporting this policy is that counting bodies undermines victims' dignity, by reducing them to numbers. An essential argument against this policy is that it denies those individuals the dignity of recognizing their sacrifice.

Reporting U.S. casualties in Iraq raises its own policy issues: Should accidental deaths be distinguished from ones directly due to hostile acts? How long should the counting period extend, when considering delayed deaths from injury, disease, or suicide? Should contract worker deaths be included? If so, should the record note whether those individuals had recently left military service? How should it treat problems attributed to post-traumatic stress disorder (Vendatam, 2005)? Should it include suicides among family members of the fallen (Wilson, 2005)?

The latest revision of the U.S. Standard Certificate of Death (U.S. National Center for Health Statistics, 2001) added, among other things, questions about pregnancy status, race, and whether tobacco use had contributed to the death. It declined to add, among other things, questions about homelessness, citizenship, health insurance, diabetes, and social support. As of September 7, 2005, the National Association of Medical Examiners (2005) Death Registry

\footnotetext{
${ }^{1}$ Human Rights Watch (2005, footnote 32) reports a communication from the press office of the MultiNational Force citing the practical difficulties of recording casualties, arguing, "It would be irresponsible to give firm estimates." That might be a valid defense for an information source criticized for any imprecision and an invalid one for an information consumer eager for any properly qualified estimate.

2 A Google search for "Tommy Franks" "body counts" yielded 12,200 hits on August 26, 2005, and 41,400 on October 29, 2006 (recognizing the imperfections in these counts).
} 
included the following "reportable" causes of death: bioterrorism agent, bomb-related death, chemical terrorism agent, in custody (in jail, not in jail), lightning strike, product tampering, (human) stampede, structural collapse, TASER used, unexplained death in adult younger than 30 years, and death caused by "unsuspected neoplasm." One can imagine the instrumental or essential purposes served (or frustrated) by the decision to include (or exclude) each of these features.

Both the Certificate of Death and the Death Registry include guidance on the professional judgment involved in their implementation. These instructions reflect experts' experience with the ambiguities of real-life circumstances (decomposing bodies, incomplete chain of custody, time pressure). They also reflect experts' awareness of the social pressures on the recording process (e.g., coroners who are also funeral directors, sensitive to families' wishes about what gets recorded; families that prohibit autopsies, for religious or criminal reasons). These guidelines are intended to afford the best chance of satisfying the value judgments expressed in deciding to consider each feature-recognizing inherent limits, such as the inferential challenges of assessing the contributory roles of causes with diffuse effects, such as tobacco or obesity.

All this effort will be misdirected without agreement on the feature set. The next section describes a general approach to defining that set so as to integrate professional expertise with social values, in ways that focus experts on the issues that matter most to users of the reports. It does so by treating casualty recording as a special case of measuring phenomena whose meaning is socially defined, by users' essential or instrumental needs.

\section{Creating reporting protocols}

\subsection{Understanding risk}

When measuring a socially defined phenomenon, each procedural choice can serve some ends, while frustrating others. An influential National Research Council (1996) report addressed these general issues in the specific context of measuring risks. It recommended that any measurement protocol be specified with an analytical-deliberative process. It begins by having technical experts analytically develop a set of potentially relevant features, based on their understanding of the risk and the concerned parties' needs. Those parties then deliberatively determine which features they want to consider, reducing or expanding the initially proposed set. Technical experts can inform these deliberations (e.g., by explaining empirical measurement problems, by estimating the costs of alternative methods). However, the choice of measures ultimately depends on the parties' value judgments. The technical experts' priorities matter only if they have stakeholder standing (i.e., if advancing their science is a legitimate goal). Other bodies have echoed variants on this procedure (e.g., Cabinet Strategy Office, 2002; Canadian Standards Association, 1997; Environmental Protection Agency, 2000; Presidential/Congressional Commission on Risk, 1998; Royal Commission on Environmental Pollution, 1998; Treasury Board, 2002).

In a precursor to these reports, the U.S. Environmental Protection Agency (1993) conducted several dozen state and regional consultations following a similar process, as part of setting its risk management priorities. In collaboration with technical experts, participants in each consultation identified a set of features characterizing the risks that mattered to them. Technical experts then assessed the risks in terms of those features. The participants used that description to make policy recommendations (e.g., how much to invest in reducing each risk, how severe to make the penalties for creating it). 
With this process, each consultation created a unique measurement procedure. Although it leads to using features that are maximally relevant to participants, such tailoring requires resources and expertise. If a panel lacks them, it might unwittingly sacrifice validity for relevance, relying on measures that fail to capture the features that it hopes to address. Having a unique procedure for each panel also reduces the comparability of their conclusions. Although the panels were asked to focus on issues that could be resolved locally, EPA has an interest in the overall consistency of its policies, such that expenditures are proportionate to the risks and the opportunities to reduce them. A uniform procedure would serve that end, as well as clarifying whether, when two panels express different priorities, the cause is differing values (regarding which features matter) or realities (regarding the size of the risks) —or just noisy measurement.

One way to balance tailoring and standardization is to offer each panel a standard set of features, as a point of departure for its deliberations. The panel can then decide how much weight, if any, to give each feature. The standard set would be based on research identifying features that generally matter to people and can be measured well (Davies, 1996; Fischhoff, 2005; Fischhoff et al., 1984; Florig et al., 2001; Morgan et al., 2001).

\subsection{Managing risks to the public}

As part of an effort to improve risk management, the British government recently endorsed a standard set of features for characterizing risks, as a complement to economic measures. This procedure was developed through consultation with stakeholder groups and the agencies that would implement it (HM Treasury, 2005). Some features in the set are compromises between ones that are important, but hard to measure, and more tractable surrogates that approximate them. The British approach is instructive, regarding the choices that must be made in creating a protocol for counting casualties.

The expected number of deaths is one obvious feature in a set characterizing risks. However, the British procedure does not treat all deaths as equal. Rather, it represents them by the Quality Adjusted Life Years (QALYs) lost with each death. This metric gives greater weight to deaths of young people (because more life-years are lost) and of healthy people (who lose higher quality years). It indirectly assigns a value to morbidity, insofar as health problems (e.g., chronic pain, paralysis) reduce the quality of people's remaining years. Recognizing that people may care about more than just the expected number and "quality" of casualties, the proposal offers six features, chosen to span the space of additional concerns: (a) how familiar citizens are with the risk, (b) how well scientists understand the processes creating and controlling it, (c) how equitably its effects are distributed, (d) how much "dread" it evokes among those contemplating it, (e) how voluntary and controllable exposure to it is, and (f) how well citizens trust those managing it. Studies have found that many other potentially relevant features of risks are strongly correlated with the ones in this set (Fischhoff et al., 1978; Lowrance, 1976; Slovic, 1987; Starr, 1969). As a result, any feature missing from the set is likely to be represented by a related one.

Each of these features might be relevant to assessing casualties in conflict zones. "Lost life years" captures some of the extra tragedy of casualties among young people. "Quality" is lost when survivors bear physical or psychological scars. Some ways of dying evoke more "dread" than others. Losses are even more painful, when they are attributed to the incompetence or callousness of one's own authorities, making them unworthy of trust. And so on.

Although it might be an interesting exercise to apply these features to recording casualties, the set emerged from a very different discourse than that associated with conflict zones. 
Specifically, it arose in response to the limits to cost-benefit accounting for project evaluation: Despite some consensus among economists about how to monetize many impacts, projects with similar costs and benefits are sometimes regulated differently. The features in the British set seek to capture the sources of these differences and subject them to explicit evaluation. However, although risk regulation deals with casualties, those are unwanted byproducts of projects expected to bring benefits. In conflicts, harm is the goal. An analyticaldeliberative framework for assessing casualties in conflict zones requires its own analysis and deliberation, recognizing that malevolence. We now consider what that analytical content might be, followed by a discussion of the deliberative process that could create and implement a protocol for counting casualties.

\section{A framework for counting casualties}

Following the analytical form, but not the content, of these approaches to defining risks, each casualty would be characterized in terms of a standard set of features. The members of that set would be determined by a deliberative process that seeks to balance tailoring (in order to address specific parties' concerns) and generality (in order to create robust methods, producing results that are comparable across conflicts).

For example, a simple set of features might be:

(nationality, military status, date of death, location).

In the Middle East conflict, a casualty might be (Israeli, non-combatant, 5/23/04, marketplace) or (Palestinian, Hamas member, 6/15/03, apartment). A more complex scheme might also include age, sex, and method (e.g., Qassam rocket, gun, improvised explosive device, suicide bomb, beating).

Developing a standard set of features would begin with technical experts (e.g., forensic pathologists, political theorists, anthropologists) preparing a set of candidates. A properly constituted body of stakeholders would then select the relevant features, starting from, but not bound by, the experts' initial proposal. That deliberative process would focus on the features that matter most to stakeholders, tempered by knowledge (provided by technical experts) of how well each can be measured-given the available science, resources, and field conditions. The standard set would have inclusion features, determining whether a casualty is considered at all, and distinguishing features, for how that consideration proceeds. Each inclusion feature defines an at-risk population.

For example, two inclusion features in the U.S. government's public reporting of casualties in Iraq appear to be nationality and military status (the first two features in (1)). Each of these features has two possible values: (U.S., non-U.S.), (military, non-military). The rules applying these inclusion features lead to considering distinguishing features only for U.S. military dead. Describing casualties in these terms may address the essential need to honor fallen American soldiers and the instrumental need to determine death benefits. It may partially address the instrumental question of whether the war is worth the sacrifice (given some measure of its benefit).

For individuals whose deaths qualify for further description, the date and location of death (the other two features in (1)) provide instrumentally useful information for charting the war's course (as in Department of Defense, 2005). The location of death might serve the essential purpose of determining whether the dead merit special honors (e.g., by dying in a particular mission). 
Not recording deaths of civilian contractors might express the essential value that military service is a prerequisite for national honors or the instrumental value that their deaths are irrelevant to evaluating the war's progress. It might also reflect a desire to avoid the instrumental value that recording contractors' deaths would have for the war's critics, whose case is advanced by a larger toll. Whatever its motives, this aspect of the U.S. casualty reporting protocol fails to serve anyone who needs that information, for essential or instrumental purposes. That might include U.S. policy makers, for whom a record of contractor deaths could reveal changes in the risk environment, relevant to anticipating resource needs and domestic support (Bergner, 2005).

Very different inclusion features were used by Roberts et al. (2004) and Burnham et al. (2006), who sought to count all Iraqi casualties from the conflict, including indirect ones due to impaired sanitation, emergency services, and healthcare. As a concession to field conditions, they intensely investigated a sample of cases, then extrapolated to the country as a whole - estimating between 400,000 and 800,000 more deaths in the three and a half years after the invasion, compared to what would otherwise have been expected. Although the professional judgment in their choice of statistical procedures has evoked some controversy, their choice of features has been little challenged - except for their not attempting to distinguish between combatants and non-combatants (defended as possibly putting interviewers at risk, without yielding trustworthy reports). The methodological debates reflected, in part, the instrumental needs of those eager to support or undermine the study's high casualty estimates (proportionate to 5-10 million excess deaths in the U.S.). From that perspective, accepting all the critics' (or all the supporters') claims would, likely, lead to similar conclusions about the scope of the casualties-although perhaps not regarding their acceptability.

The next two sections illustrate the analytical issues in counting casualties, as they emerge in the protocols applied in two Middle East conflict zones. Our inferences regarding the values motivating these protocols attempt to give a feeling for the issues that such efforts must confront, not to second-guess, criticize, or praise these efforts. We hope that this analysis will facilitate the recording of casualties in all conflict zones.

\section{Case study 1: Iraq Body Count}

\subsection{Introduction}

The Iraq Body Count (IBC) project seeks to "establish an independent and comprehensive public database of media-reported civilian deaths in Iraq resulting directly from military action by the USA and its allies," [http://www.iraqbodycount.net/background.htm] ${ }^{3}$ in the period beginning January 1, 2003. To this end, it includes any civilian death reported by two or more members of a list of recognized media sources. On January 1, 2006, IBC reported a minimum of 27,707 and a maximum of 31,232 civilian deaths in Iraq.

The IBC's primary inclusion criteria are date (after January 1,2003) and civilian status. Its purpose is primarily essential: "This project aims to record single-mindedly...one key and immutable index of the fruits of war: the death toll of innocents. ...It is to these all too easily disregarded victims of violence that Iraq Body Count is dedicated, and we are resolute that they, too, shall have their memorials." Two instrumental goals are (a) allowing users to "where possible. . establish whether there are grounds for criminal proceedings"

\footnotetext{
${ }^{3}$ All quotations are from this site, accessed most recently on January 1, 2006.
} 
and (b) promoting "public understanding, engagement and support for the human dimension in war."

The media reports used by IBC do not address any standard set of features. Rather, they reflect reporters' (and editors') intuitive notions and professional norms regarding the features that their audiences value, within the constraints of what they can collect. Faced with this reality (and its own resource limits), IBC developed a small set of standard features that it could extract reliably and transparently, designed "to ensure that each incident is differentiated from proximate incidents with which it could be potentially confused." The features are:

(civilian status, number of deaths, date, time, location, target, weapon).

The features are defined in ways intended to require a minimum of professional judgment. For example, the "target" is that stated by military sources. Users can interpret that characterization as they wish. The record lists each report's source, again allowing users freedom of interpretation (e.g., if they believe that some sources are biased, by politics, intimidation, or bribery).

As mentioned, the first feature, the victims' civilian status, is an inclusion criterion, complementing the U.S. policy of recording only U.S. military deaths. Civilian status has essential value, for honoring those who died, and instrumental value, for making decisions about the war. Professional judgment is needed when applying this feature during a civil war or insurgency, insofar as civilian dress does not guarantee non-combatant status. Indeed, combatant status may be deliberately obscured (e.g., by those who act as couriers or hide arms). Some roles are inherently ambiguous status (e.g., officials in the civilian arm of a military organization, truck drivers employed by military contractors). Additional professional judgment is needed when determining whether deaths are ones that "the Occupying Authority has a binding responsibility to prevent under the Geneva Conventions and Hague Regulations. This includes civilian deaths resulting from the breakdown in law and order, and deaths due to inadequate healthcare or sanitation." [Bold in original.]

For any feature outside the IBC set, analogous questions arise, regarding the value judgments associated with its inclusion and the professional judgments associated with its application. For example, victims' religion and ethnic identity might interest some parties. Those familiar with Iraqi realities might be able to infer those features, from the media reports used by IBC, with enough confidence to have some instrumental value (e.g., as measures of civilian morale and combatant strategies). Including these features would violate an essential value for those who would treat all civilians equally, while honoring an essential value for those who care only about their own kind.

\subsection{Analytical perspectives}

Figure 1 shows the number of deaths recorded in the IBC database, by month. As mentioned, IBC has standardized some aspects of the professional judgment needed to apply its protocol. In addition to requiring each incident to appear in two approved sources (with some explicit exceptions), it records maximum and minimum values when more than one appears. For some kinds of ambiguity, it specifies interpretative rules that it characterizes as "conservative," in the sense of tending to understate numbers. For example, "when wording used in both reports refers to 'people' instead of civilians, we will include the total figure as a maximum but enter ' 0 ' into the minimum column unless details are present clearly identifying some or all of the dead as civilian." Such precision about uncertainty expresses an essential value, of 


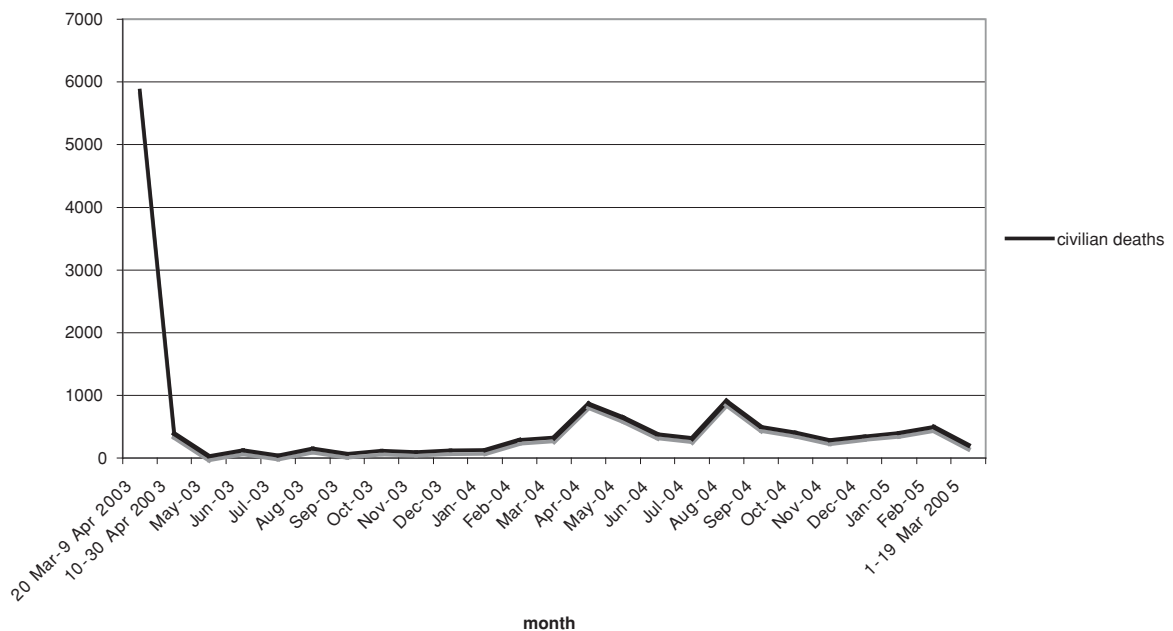

Fig. 1 Civilian deaths in Iraq, by month (with partial initial and final periods). Source: Dardagan et al. (2005)

commitment to accuracy and transparency. It should also facilitate the instrumental goal of effective decision making, which requires understanding data quality. The range of estimates is so narrow that few choices would be sensitive to whether the high or low value is used. However, that need not have been the case.

Figure 1 includes the third feature recorded for each report, the date of the deaths. In the context of each report, it is an essential feature, documenting another aspect of that event. In the aggregate, it has instrumental value, allowing deaths to be related to other events. When an entry summarized multiple events, our professional judgment was to treat them as occurring at a constant rate during the period. That practice addresses the instrumental goal of revealing broad trends over time, while obscuring responses to specific events. The peak in March and April 2003 reflects the initial invasion, while the smaller peak in April 2004 reflects the first assault on Fallujah. ${ }^{4}$

The fourth feature, time of day, has similar essential value for documenting each incident. It has instrumental value for evaluating hypotheses about patterns in violent acts (e.g., at the beginning of the work day, as markets close, during prayers).

Each of the other IBC features (target, location, and weapon) could also have both essential and instrumental value. For example, attacks on holy places or clerics could be intrinsically important, as well as revealing their perpetrators' strategies. Suicide bombers (as weapons) might reflect (or violate) essential values, as well as reveal strategies and social currents (Atran, 2006). They are important inputs to Dardagan et al.'s (2005) analyses of these casualties.

Figure 2 presents a subset of the multiple death reports: monthly totals of "violent killings" recorded at the Baghdad city morgue. These reports represent one location, with perhaps the most consistent reporting practices over time. ${ }^{5}$ They have value for those who care about deaths in the capital. They also provide input to the professional judgment needed to

\footnotetext{
${ }^{4}$ IBC used special procedures for Fallujah: http: //www.iraqbodycount.net/details/x360_notes.php.

${ }^{5}$ Sly (2005) reports the morgue numbers for June and July 2005 as 879 and 1100, respectively, with $60 \%$ from shootings. See also Fisk (2005) and Marcus (2006), among others.
} 


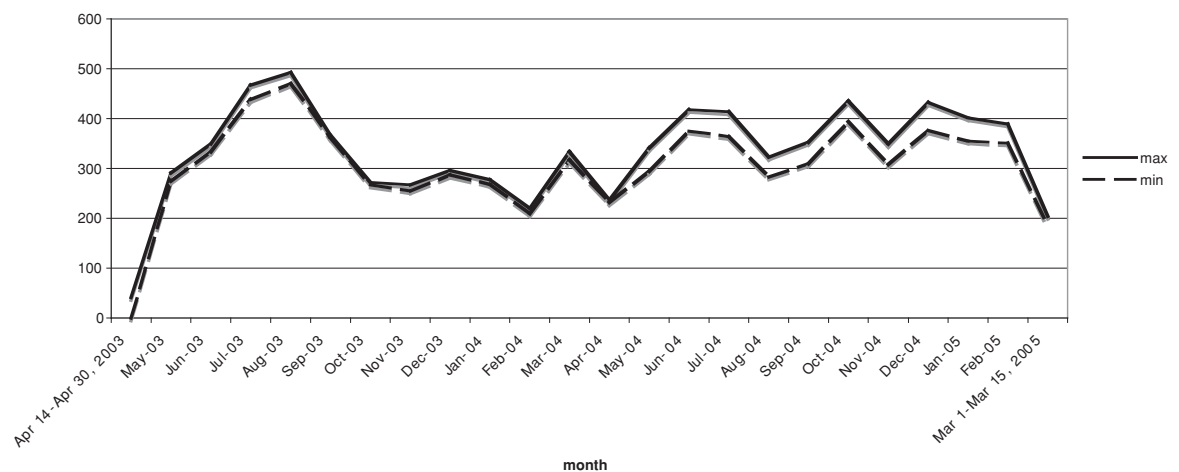

Fig. 2 Violent deaths recorded at Baghdad city morgue, by month (with partial initial and final periods). Source: Dardagan et al. (2005)

interpret all reports. For example, Baghdad morgue deaths were high compared to those in the news media (Fig. 1) soon after the invasion, suggesting underreporting. Their general level parallels that in the media from late 2003 on, suggesting stabilized reporting. If so, then one can more confidently try to explain patterns over that period. For example, the seemingly inverse patterns during the Fallujah campaigns suggest that the situation in Baghdad may have affected and been affected by events in Fallujah; perhaps a shift in violence, perhaps a shift in reporters' attentions.

\subsection{Summary}

IBC seeks to describe each death in terms of six features: noncombatant status, date of death, time of death, target, location, weapon. Each feature can have essential or instrumental value, depending on how the reports are used. Each reflects IBC's view of what matters, conditioned on what measurement is possible, given its resources and source material. IBC formalizes some of the professional judgment that the recording requires. Dardagan et al. (2005) specify additional aspects in their analyses of these reports, as other researchers would have to do when conducting their own analyses. If IBC were party designing a standard protocol collaboratively, it would want to ensure that its features are retained, while perhaps having to accept other features that it found unimportant or even offensive.

\section{Case study 2: B'tselem: casualties in second intifada}

B'tselem (2005), an Israeli human rights NGO, has compiled casualty statistics for another ongoing conflict, the second intifada. B'tselem characterizes deaths in terms of five features that we have extracted from their 13-category scheme:

(nationality of dead, military status of killer, age of dead, location, date).

Nationality is an essential feature for some people to consider-and for others to ignore (in order to treat deaths among all peoples equally). Including it serves the former, while offending the latter. Those who deny the essential value of nationality might still find it to 
have instrumental value, providing clues to the nature of the conflict and, perhaps, ways to reduce it.

B'tselem makes no distinction between Palestinian civilians and combatants. Some people might view that omission as failure to consider a feature with both essential and instrumental value. As in Iraq, assessing combatant status would require professional judgment, given a civilian population with many people mobilized for the struggle and some willing to conceal combatants. Conversely, B'tselem does distinguish among Israeli civilians and combatants. Some people might find that distinction objectionable, arguing that Israel's whole society is mobilized, not to mention those civilians who are soldiers on leave or in the reserves. Some people might object to treating Israelis and Palestinians differently in any way. In assessing this feature, B'tselem's professional judgment is to categorize Israeli casualties as combatants only if on active duty.

In terms of age of death, B'tselem distinguishes between adults and minors. Dardagan et al. (2005) saw a need to distinguish minors under age 2 from older ones. One might also choose to distinguish older adults, for essential reasons (respecting the elderly) or instrumental ones (identifying those less likely to be combatants).

In terms of the location, B'tselem distinguishes between deaths in Israel and the occupied territories. That distinction matters to those holding positions on the legitimacy of each side's presence in different places - and the essential meaning of deaths there. In instrumental terms, the location captures some of the conflict's development.

As with IBC, date of death is unlikely to have essential value (except perhaps for identifying deaths in holy periods). However, it should have instrumental value for understanding the conflict (e.g., fluctuations over time, time dependencies in deaths on the two sides, changes in relative rates).

\subsection{Analysis}

We present data for killings of Israelis by Palestinians and vice versa, for September 29, 2000August 7, 2005, from http://www.btselem.org/English/Statistics/Casualties.asp. ${ }^{6}$ (The data set also includes killings of Palestinians by Palestinians, among other statistics.) We aggregate these data in several ways, selected to illuminate the essential and instrumental needs that might be served by these features, without presuming to know B'tselem's philosophy. Figure 3 depicts the data in terms of the nationality of the dead and the date of death, grouped by quarter. The time period for aggregating reports is a matter of professional judgment. Smaller periods can reveal finer changes, but have greater chance fluctuations.

Those who distinguish the dead by nationality may want to examine each side's deaths more closely. Figure 4 divides Palestinian deaths according to two additional features: military status of the killer and location of death. The top curve dominates the figure. It presents "Palestinians killed by Israeli security forces in the occupied territories" (in B'tselem's language). The other two curves present Palestinians killed by Israeli security forces in Israel and by Israeli civilians in Israel or the territories. Although relatively rare (in this violent context), these deaths might have particular essential or instrumental value (e.g., if the 36 killings in the last category are seen as representing a high level of vigilante

\footnotetext{
${ }^{6}$ The data have two known gaps: (1) data on Israeli soldiers killed by Palestinians within Israel, for May and June 2005. Historically, the monthly number has typically been between 0 and 2, peaking at 13 . (2) The July 2005 report of two Palestinians killed by Israeli civilians does not specify the age group of the dead. In previous months, the number of minors has typically been zero and never more than one.
} 


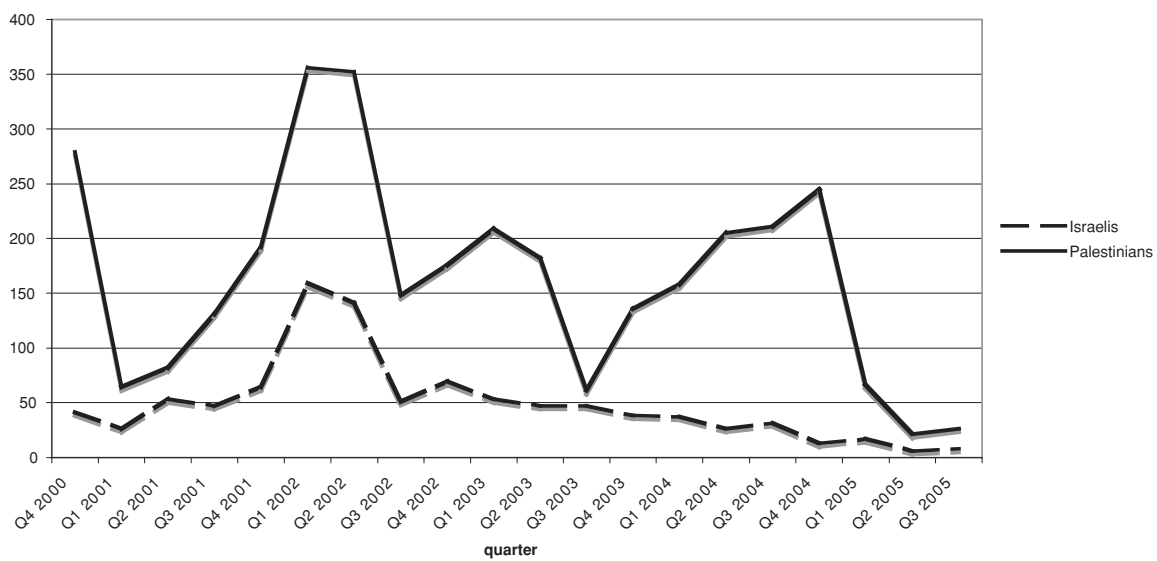

Fig. 3 Israeli and Palestinian deaths from armed conflict, by quarter (with partial initial and final periods). Source: B’Tselem (2005)

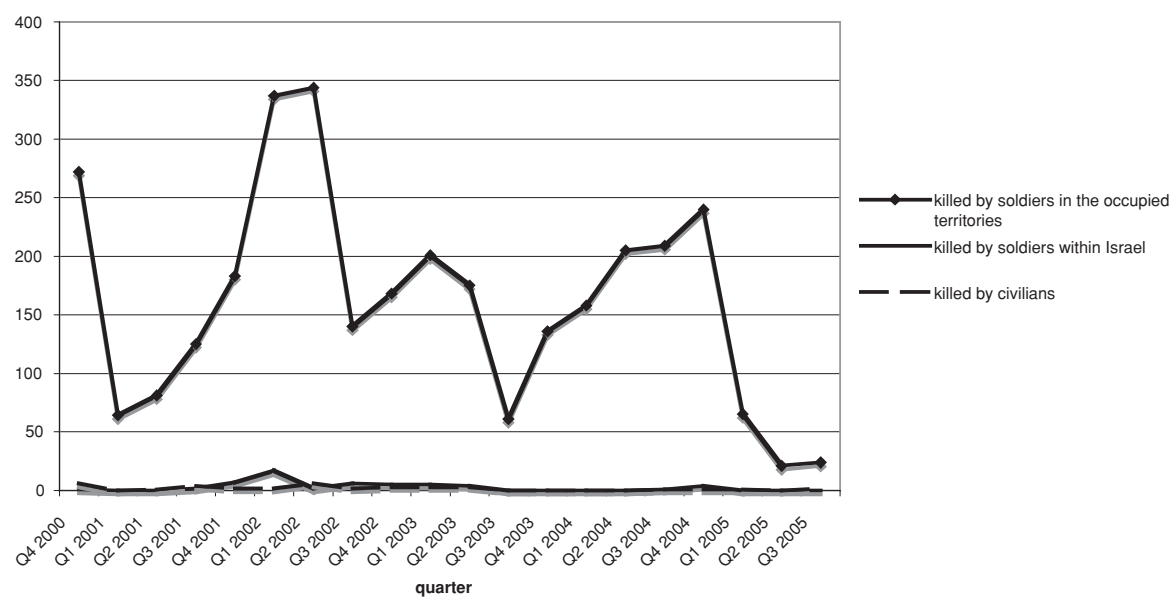

Fig. 4 Palestinians killed by Israelis, by quarter (with partial initial and final periods). Source: B'tselem (2005)

action). Fuller analysis might consider exposure to these risks, that is, the extent to which Palestinians are safer while in Israel or just less likely to be there.

Figure 5 shows analogous data for Israeli dead. The largest category is civilians killed within Israel, followed by security forces killed in the occupied territories, civilians killed in the territories, and security forces killed within Israel. The differences in rates across locations are much smaller for Israelis than for Palestinians. Where deaths occur has essential value for those who view Israeli activities in the occupied territories as illegitimate or imperative. Location would have instrumental value, for understanding the course of the conflict, if, for example, deaths in Israel evoke more vigorous reactions-because they are seen as threatening the entire population, not just settlers. Here, too, a fuller analysis would consider exposure, for Israelis in Israel and the territories. Risk perceptions may be disproportionately influenced by the total number of incidents, relative to the number of people exposed (Slovic, 


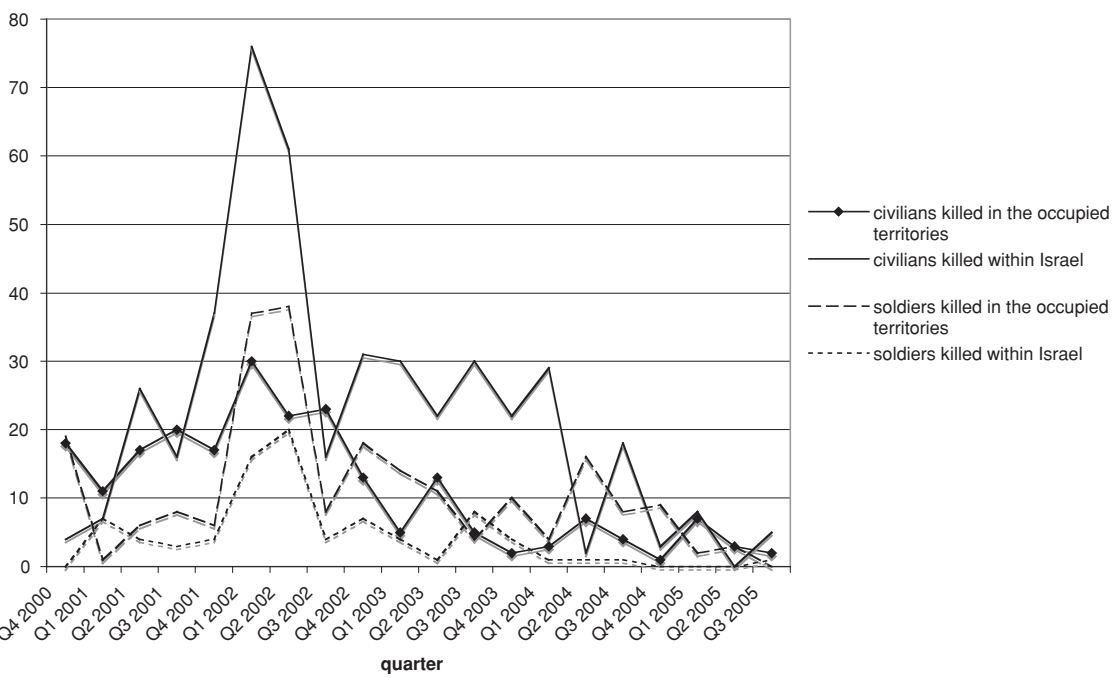

Fig. 5 Israelis killed by Palestinians, by quarter (with partial initial and final periods). Source: B'tselem (2005)

1987; Tversky and Kahneman, 1974; Viscusi and Zeckhauser, 2004), so that both raw and relative frequencies may have instrumental value for predicting public reactions.

Figure 6 shows deaths among minors, relative to overall deaths for both peoples. This distinction has essential value for those who feel special revulsion when young people are killed. It has instrumental value for those who believe that such deaths have special impacts (on policy, hatred, education, etc.), but not for those who see either society as so fully mobilized that it no longer matters who dies. A fuller analysis might compare the proportions of deaths among minors in the two populations over time. A matter of professional judgment

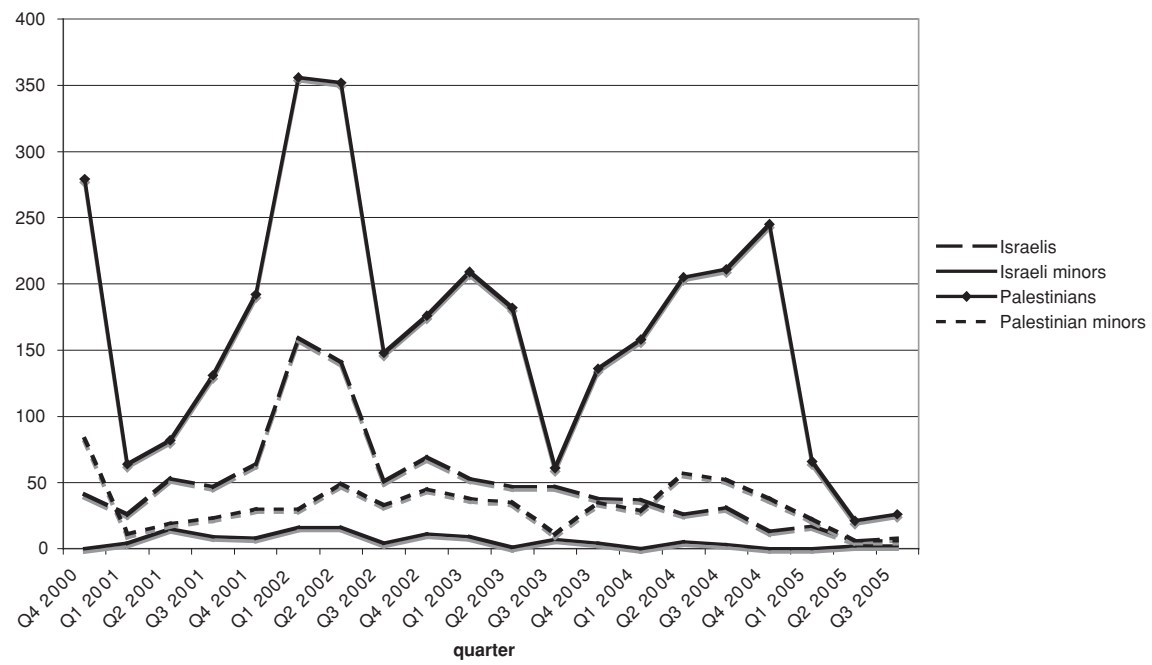

Fig. 6 Israeli and Palestinian deaths, by age. Source: B'tselem (2005) 
is using the legal age of majority (18) as the cutoff, which might reflect maturity, autonomy, military status, or other considerations.

\subsection{Summary}

B'tselem uses a complex coding scheme, from which we extracted five core features. Each could have both essential and instrumental value, depending on users' needs. To some extent, any feature with essential value for Palestinians or Israelis has instrumental value for observers, insofar as it predicts future events, even if they disagree about its interpretation (e.g., the status of the territories). We have suggested some topics for such research; others are possible (e.g., the effects of targeted assassinations or suicide bombings). We have also indicated some controversial aspects of deciding which features to include and ignore, as well as their specification.

Radlauer (2002) approaches the same recording task in an analytically similar way, using features that he selects in an avowedly biased way. Believing that others' data are unfair to Israel, he identifies features that he expects to increase the sense of tragedy for Israeli deaths and lessen that for Palestinian deaths. One such feature is the victim's sex (not considered by B'tselem). Adding this feature reveals Palestinian deaths to be overwhelming male, while about one third of Israeli dead are women. A second added feature refines "age" to include more than just the minor-adult distinction. Looking at finer gradations reveals that dead Israeli adults are much more likely to be over 45, compared to Palestinian adults. Adding these two features might serve both essential purposes (for those differentially pained by deaths of women and older people) and instrumental ones (e.g., by clarifying combatant status).

Radlauer specifies procedures for reducing the role of professional judgment in assessing these features and describes his attempts to create neutral category labels. In one sense, having more information about casualties should only be helpful. Those who disagree about the importance of a feature (e.g., sex) or distinction (e.g., precise age) can just ignore it. However, if Radlauer's refinements tip observers' views in one direction, then adding yet more features might tip it back. Given adequate resources, each party could create its own recording protocol. However, where that condition is not met (e.g., Radlauer describes his limited access to Palestinian data), the recording protocol can be a source of added tension.

\section{Conclusions}

Measuring social phenomena is, inevitably, a value-laden act. It determines whose data get collected, recognizing the legitimacy of their concerns and helping them to fulfill their missions. Measurement protocols reflect a balance of power, perhaps informed by scientific understanding. Recording casualties in conflict zones confronts special cases of these general issues. We propose a framework for addressing them explicitly, drawing on experiences in risk analysis.

The case studies illustrate the issues revealed by implementing such a framework. Each suggests the essential and instrumental value assumptions underlying an existing recording protocol. Although the two sources do not reference one another, they address similar features and offer similar guidance regarding the professional judgment involved in their application. Both consider whether the dead person was a combatant (IBC excludes those who appear to be; B'tselem marks the distinction). Both consider the number, date, and location of the death (with IBC preserving finer distinctions). IBC lists the weapon used; B'tselem does 
not. A door-to-door survey in Iraq, conducted by CIVIC in 2003 (http://civilians.info/iraq/), had similar features (age, sex, date of death, location of death, war event), along with additional ones, focused on essential features of each deceased's life (marital status, occupation, monthly income, dependents).

Assuming that they are executed faithfully, such protocols should only be for the good. They offer data that some parties need and others can ignore. However, the processes prompting their creation are troubling, insofar as each was motivated by dissatisfaction with official recording procedures. Any fight over measurement adds to the tension and distrust of a conflict. As a result, there may be value to having a standard protocol, whose adoption would be, in legal terms, a rebuttable presumption. Like the British approach to characterizing risks, that standard protocol would serve as a point of departure, which the parties could adapt—or reject. In some cases, adopting a default protocol might allow the parties to avoid directly facing difficult value issues, by saying that they are following an international convention or custom.

When the standard protocol is used, the legacy of previous applications should facilitate data collection and analysis. When changes are made, that should be with a better grasp of the professional and value judgments involved, compared to creating a protocol ad hoc. Having a collection of reports, describing casualties in comparable terms, should improve the understanding of conflicts. If that knowledge reduces their toll, then it will honor the dead, adding to the essential value of recording their deaths.

\subsection{A proposal}

The analytical-deliberative process advocated by the National Research Council (1996) offers a structured way to identify whatever common ground exists, in terms of generally acceptable measurement protocols. Its first step is identifying the parties with standing to affect the procedure. Exclusion may reflect a value judgment (i.e., that their opinion does not matter) or a professional judgment (i.e., that they are not qualified to represent their values). The second step is having technical experts prepare a draft proposal, drawing on their understanding of the conflict and the parties' needs. The third step is convening the parties to revise the draft proposal, identifying the breadth and depth of measurement that provide the best investment of available resources.

Although technical specialists' expertise is essential to this process, their own values are not relevant, unless given standing. That is more likely for their instrumental values (which could produce understanding that informs policy choices) than for their essential values (except insofar as they reflect those of ordinary citizens). The experts would need to reassure lay participants that they have not rigged the procedure in some subtle way, as has been alleged with risk analysts (O'Brien, 2000).

The institution convening such a process must be seen as both ethically neutral and technically competent. That is, it must respect all features that the parties value and understand how well different measurement procedures capture them. In the context of counting casualties, that requires expertise in the social, cultural, religious, political, and economic features that have essential value for the parties, as well as in the selection of features with instrumental value for understanding conflicts.

Preparing an analytical-deliberative process can pursue parallel methodological and institution-building tracks, with the former developing draft protocols to use in venues created by the latter. Thus, the method (which requires "just" material resources and technical expertise) would be ready, when the venue (which requires willing parties) exists. Proceeding 
in parallel allows institutional negotiations to inform method development, while creating prototypes that help to explain the process.

The method is ready for the parties' consideration when it has a complete set of possible features, along with at least rudimentary assessment procedures. Its preparation should include field tests, with individuals drawn from the target audiences, in order to improve its practicality and acceptability (e.g., by revealing unintended sensitivities to how features are labeled). Both IBC and B'tselem attempt to describe their features as literally as possible, in order to avoid taking sides (e.g., in situations where one person's terrorist is another's freedom fighter). Their success is an empirical question.

The institutional arrangements for deliberating a protocol are ready when the parties have accepted the ground rules for the discussion. Those rules should include who represents each party, how public to make the proceedings, how to represent residual disagreements, and how binding the conclusions will be. As mentioned, one possibility is including as many features as possible, within the resource constraints on measurement. Doing so allows each party to satisfy its instrumental and essential needs, by considering the features that it values and ignoring the rest.

Looking at the common elements of the recording protocols considered above, the standard representation might include, at a minimum, for each dead person:

(nationality, combatant status, age, sex, family status)

and for each incident:

(date, location, weapon, combatant status of killer).

Where protocols share a feature, they sometimes differ in details, such as which critical ages to consider (2? 18? 45? 65?). As with the choice of features, an analytical-deliberative process might be served best by preserving as many details as possible, among those with essential or instrumental value for any party. Then, each party can use whichever details address its needs. A successful process should evoke a spirit of compromise, aided by technical experts able to identify efficient ways to achieve multiple objectives. That design could take advantage of the parties' different strengths in data collection and analysis. For example, government record keepers may have more resources and better-trained staff. NGOs may have special credibility with affected communities, allowing them to elicit candid reports on sensitive topics (e.g., cause of death, ethnic background, immigration status) and gain access to places too dangerous for officials to visit. Collaboration over the protocol might further understanding among the parties, just as other communications among technical experts (e.g., weapons inspectors, hotline operators) have opened channels between otherwise hostile nations.

\section{Hurricane Katrina: A Coda}

Many observers likened the aftermath of Hurricane Katrina to a war zone. Even before the waters had begun to be pumped from New Orleans, concerns arose regarding the counting of its dead. Charges arose that not all casualties would be counted, in terms echoing those heard about Iraq and fed, similarly, by reports of journalists being denied access to observe the dead 
(Neal, 2005; Vega, 2005) ${ }^{7}$ and of contracts being let to a firm close to the Bush Administration (Kenyon International). Contracting with any commercial firm was problematic for those who felt that volunteers should prepare the dead for burial (Bunch, 2005; Confehr, 2005).

On September 9, 2005, the National Association of Medical Examiners (2005) expanded its Death Registry to include hurricane-related deaths. Adding that feature could have served the essential purpose articulated by Dr. Louis Cataldie, Louisiana's chief medical examiner, "I think it's important for everybody to understand that it's about the individual. It's about the little lady in the Superdome in all that filth who looks at you and you can't do anything for. And somebody hands you a limp kid. And when you come back to her, she's dead. I don't want people to lose track of that. We handle every person as the individual and with the dignity they deserve" (O'Neill, 2005).

However, the Death Registry goes further, distinguishing between fatalities directly and indirectly due to the hurricane. The former include deaths like drowning; the latter include death from cardiovascular disease exacerbated by relocation or traffic accidents during evacuation. ${ }^{8}$ This distinction, presumably, serves instrumental needs, such as resolving insurance and liability claims or focusing after-incident reviews, aimed at future preparations. Whatever its purposes, the protocol benefits from the quality assurance provided by medical examiners, implementing consensually defined procedures (Centers for Disease Control, 2003; U.S. Department of Justice, 1999; Wecht and Weedn, 2005). Some of their best work in Iraq has gone into exhuming Sadaam Hussein's victims (Drew and Mabile, 2005).

Acknowledgments. Research support from the National Science Foundation (SES-0433152, SBE-0527396) and the John D. and Catherine T. MacArthur Foundation is gratefully acknowledged, as are comments from Beth DaPonte, Keith Florig, Barry Pavel, Roger Peterson, Kiron Skinner, Victor Weedn, Richard Wilson, and members of the World Federation of Scientists Permanent Monitoring Panel on Terrorism. The views expressed are those of the authors.

\section{References}

Atran, Scott. (2006, Spring). “The Moral Logic and Growth of Suicide Terrorism,” The Washington Quarterly $29,127-147$.

Bergner, Daniel. (2005, Aug. 14). "The Other Army," New York Times Magazine 28-35, 50-58.

B'tselem. (2005). Statistics. Jerusalem: The Israeli Center for Human Rights in the Occupied Territory.

Bunch, Will. (2005, September 13). "Where Are the Funerals?" PNonline. http://www.pnionline.com/ dnblog/attytood/archives/002361.html.

Burnham, Gilbert, Riyahd Lafta, Shannon Doocy, and Les Roberts. (2006, October 12). "Mortality after the 2003 Invasion of Iraq: A Cross-sectional Cluster Sample Survey." The Lancet, DOI:10.1016/S01406736(06)69491-9.

Cabinet Strategy Office. (2002). Risk and Uncertainty. London: Author.

Canadian Standards Association. (1997). Risk Management Guidelines for Decision Makers (Q850). Ottawa: Author. 7 This text from a September 14 CNN interview (by Wolf Blitzer of his producer Peter Tedeschi) suggests the
kinds of concern: "Well Wolf, we were just in Long Beach, Mississippi, west of Gulfport a few hours ago.
And we're seeing barbed wire strewn across the entire length of the city about a half mile up from the Gulf
of Mexico. So when it's completed, we will see about four and a half miles of rolling barbed wire by a half
mile down to the water. What security guards there are telling us is that they want to keep looters out. But
what some military police told me privately was that they expect to find a lot of bodies in the area, that they're
finding a debris field where very nice, middle to upper middle class homes once existed. And that they can't
even get into the debris field in order to be able to find the bodies."
${ }^{8}$ The singer Clarence Gatemouth Brown was one of those indirect fatalities, evacuating just before the storm
and dying from heart problems, sometime after learning that his home had been destroyed (Ratliff, 2005). 
Centers for Disease Control. (2003). Medical Examiners' and Coroners' Handbook on Death Registration and Fetal Death Reporting. Hyattsville, MD: Author.

Confehr, Clint. (2005, September 10). "FEMA Mortuary Move Irritates Volunteer," Shelbyville Times-Gazette.

Conyers, John. (2005, December 7). "Members of Congress Ask Bush to Stop Undercounting U.S. Casualties." Washington, DC: U.S. Congress.

Daponte, Beth O. (2003). "Why Estimate Direct and Indirect Casualties from War? The Rule of Proportionality and Casualty Estimates." Unpublished manuscript.

Daponte, Beth O. (1993). "A Case Study in Estimating Casualties from War and Its Aftermath: The 1991 Persian Gulf War," PSR Quarterly 3(2), 57-66.

Dardagan, Hamit, John Sloboda, Kay Williams, and Peter Bagnall. (2005). "A Dossier of Civilian Casualities." http: //www.iraqbodycount.org/press/pr12.php.

Davies, Clarence (Ed.). (1996). Comparing Environmental Risks. Washington, DC: Resources for the Future.

Department of Defense. (2005, October). Measuring Stability and Security in Iraq. http://www.defenselink. mil/news/Oct2005/d20051013iraq.pdf.

Drew, Christopher and Tresha Mabile. (2005, June 7). "Desert Graves Yield Evidence to Try Hussein,” New York Times, A1 \& A10.

Environmental Protection Agency. (1993). Guide to Risk Comparison Processes. Washington, D.C.: Author.

Environmental Protection Agency. (2000). Toward Integrated Environmental Decision Making (SAB-EC-00011). Washington, D.C.: Author.

Epstein, Edward. (2002, March 23). "Success in Afghan War Hard to Gauge: U.S. Reluctance to Produce Body Counts Makes Proving Enemy's Destruction Difficult," San Francisco Chronicle.

Fischhoff, Baruch. (2005). "Cognitive Processes in Stated Preference Methods." In Karl-Göran Mäler and Jeffrey Vincent (eds.), Handbook of Environmental Economics (pp. 937-968). Amsterdam: Elsevier.

Fischhoff, Baruch, Paul Slovic, Sarah Lichtenstein, Stephen Read, and Barbara Combs. (1978). "How Safe Is Safe Enough? A Psychometric Study of Attitudes towards Technological Risks and Benefits," Policy Sciences 8, 127-152.

Fischhoff, Baruch, Stephen Watson, and Chris Hope. (1984). "Defining Risk," Policy Sciences 17, 123-139.

Fisk, Robert. (2005, August 17). "Up to 20 Per Cent of the Bodies Are Never Identified, Many of the Dead Have Been Tortured or Disfigured." The Independent. http://news.independent.co.uk/world/ fisk/article306436.ece.

Florig, H. Keith, M. Granger Morgan, Kara M. Morgan, Karen E. Jenni, Baruch Fischhoff, Paul S. Fischbeck, and Michael DeKay. (2001). "A Deliberative Method for Ranking Risks (1): Overview and Test Bed Development," Risk Analysis 21, 913-922.

Goodin, Julia and Randy Hanzlick. (1997). "Mind Your Manners: General Results from the National Association of Medical Examiners Manner of Death Questionnaire," American Journal of Forensic Medical Pathology 18(3), 224-227.

Graham, Bradley. (2005, October 24). "Enemy Body Counts Revised: US Is Citing Tolls to Show Success in Iraq," Washington Post, p. A1.

Hanzlick, Randy. (2005). "Quality Assurance Review of Death Certificates: A Pilot Study," American Journal of Forensic Medical Pathology 26(1), 63-65.

HM Treasury. (2005). Managing Risks to the Public. London: Author.

Holt, James. (2006, March 12). "The Way We Life Now: Math Murders." New York Times Magazine.

Human Rights Watch. (2003). "Hearts and Minds: Post-war Civilian Deaths in Baghdad Caused by U.S. Forces," Human Rights Watch 15(9E).

Human Rights Watch. (2005). "A Face and a Name: Civilian Victims of Insurgent Groups in Iraq," Human Rights Watch, 17(9E).

icasualties.org. (2003). Where Do the Numbers Come from? http://icasualties.org/oif/Methodology.aspx.

icausalties.org. (2005). Partial list of contractor casualties in Iraq. http://icasualties.org/oif/Civ.aspx

Institute of Medicine. (2003). Medicolegal Death Investigation System: Workshop Summary. Washington, D.C.: National Academy Press.

Lowrance, William. (1976). Of Acceptable Risk. Los Angeles: Kaufmann.

Marcus, Carla. (2006, May 15). "Identifying Corpses," http://onthescene.msnbc.com/baghdad/2006/05/ identifying_cor.html.

Morgan, Kara M., Michael L. DeKay, Paul S. Fischbeck, M. Granger Morgan, Baruch Fischhoff, and H.K. Florig. (2001). "A Deliberative Method for Ranking Risks (2): Evaluation of Validity and Agreement among Risk Managers," Risk Analysis 21, 923-938.

Neal, Terry M. (2005, September 8). "Hiding Bodies Won’t Hide the Truth," Washington Post.

National Association of Medical Examiners. (2005). Death Registry. www.orainc.com/ndr.

National Research Council. (1996). Understanding Risk. Washington, D.C.: National Academy Press.

O’Brien, Mary. (2000). Risk. Cambridge: MIT Press. 
O’Neill, Ann. (2005). "Identifying Victims a Grueling Task: Every Corpse Gets a Number, Not All Will Get a Name," http://www.cnn.com/2005/US/09/09/katrina.morgue/index.html.

Peterson, Roger D. (2002). Understanding Ethnic Violence. New York: Cambridge University Press.

Presidential/Congressional Commission on Risk. (1998). Risk Management. Washington, D.C.: Author.

Radlauer, Don. (2002, September 29). "An Engineered Tragedy: Statistical Analysis of Casualties in the Palestinian-Israeli Conflict," International Policy Institute for Counter-Terrorism. http://www.ict.org.il/ articles/articledet.cfm?articleid $=439$.

Ratliff, Ben. (2005, September 12). “Guitarist Clarence Gatemouth Brown Dies at 81," New York Times.

Roberts, Lee, Riyadh Lafta, Richard Garfield, Jamal Khudhairi, and Gilbert Burnham. (2004). "“Mortality” Before and After the 2003 Invasion of Iraq: Cluster Sample Survey.” The Lancet 364, 1857-1864.

Royal Commission on Environmental Protection. (1998). Setting Environmental Standards. London: Author.

Sachs, Jeffrey. (2004, December 2). "Iraq's Civilian Dead Get No Hearing in the United States." Daily Star (Lebanon), http://www.dailystar.com.lb/article.asp?edition_id = 10\&categ_id = 5\&article_id = 10594 .

Slayman, A.L. (1996, October 16). Reburial Dispute. http://www.archaeology.org/online/news/kennewick. html.

Slovic, Paul. (1987). "Perceptions of Risk," Science 236, 280-285.

Sly, Liz. (2005, August 11). "Iraq in Transition: Bombs Bad Enough, But Guns Are Worse. Death Toll from Shootings Soars." Chicago Tribune.

Starr, Chauncey. (1969). "Social Benefit Versus Technological Risk," Science 165, 1232-1238.

Tavernise, Sabrina. (2005, October 30). "US Quietly Issues Estimate of Iraqi Civilian Casualties,” New York Times.

Treasury Board. (2002). Communications Policy of the Government of Canada. Ottawa: Author.

Tversky, Amos, and Daniel Kahneman. (1974). "Judgment under Uncertainty: Heuristics and Biases," Science $185,1124-1131$

U.S. Department of Justice. (1999). Death Investigation: A Guide for the Scene Investigator. Washington, D.C.: Author.

U.S. National Center for Health Statistics, Division of Vital Statistics. (2001). Report of the Panel to Evaluate the U.S. Standard Certificates. Washington, D.C.: Author.

Vega, Cecilia M. (2005, September 13). “As Bodies Recovered, Reporters Are Told 'No Photos, No Stories,"” San Francisco Chronicle.

Vendatam, Shankar. (2005, December 27). "A Political Debate on Stress Disorder As Claims Rise, VA Takes Stock," Washington Post.

Viscusi, W. Kip, and Richard Zeckauser. (2004). "The Denominator Blindness Effect: Accident Frequencies and the Misjudgment of Recklessness," American Law and Economics Review 6(1), $72-94$

Walzer, Michael. (1992). Just and Unjust Wars: A Moral Argument with Historical Examples (2nd edition). New York: Basic Books.

Wecht, Cyril H. and Victor W. Weedn. (2005). "Forensic Pathology.” In Cyril H. Wecht (ed.), Forensic Science and Law: Investigative Applications in Criminal, Civil and Family Justice. Sudbury: International.

Wilson, Jamie. (2005, October 26). "Casualty of a War a World Away," The Guardian. 